\title{
The Nordic Difference: Job Quality in Europe 1995-2010
}

I Tomi Oinas')

Post-doctoral researcher, Department of Social Sciences and Philosophy, University of Jyväskylä, Finland

I Timo Anttila

Docent, Department of Social Sciences and Philosophy, University of Jyväskylä, Finland

I Armi Mustosmäki

Researcher, Department of Social Sciences and Philosophy, University of Jyväskylä, Finland

I Jouko Nätti

Professor, Department of Social Research, University of Tampere, Finland

\begin{abstract}
Previous empirical research has pointed out that Nordic countries are distinguished from the rest of Europe in terms of job quality. On the other hand, it has been debated whether, in the longer run, the Nordic welfare state is able to insulate workers from globalization effects. This article investigates whether Nordic countries have retained their advantageous position concerning job quality compared with other EU countries. Empirical analyses are based on the European Working Conditions Survey collected in 1995, 2000, 2005, and 2010. We use data on employees in the 15 member states of the EU prior to enlargement in 2004 ( $n=61,457)$. The results partly confirm previous findings of high job quality in the Nordic countries. However, there are clear differences between Nordic countries. To be precise, Denmark stands out from the rest of Europe and other Nordic countries with its higher level of job quality.
\end{abstract}

\section{KEY WORDS}

Job quality / comparative study / Europe / Nordic countries / working conditions

\section{Distinctiveness of the Nordic countries}

lobal competition, technological change, and the deregulation of industrial relations are common developments throughout the industrial world and are seen as unifying the conditions and experiences of work in varying countries. Meanwhile, empirical research has shown that there is a notable variation in job quality between countries. Comparative research literature has tried to explain the differences between countries with reference to diverse sets of institutional frameworks, which could mediate the pressures of global change in production conditions and industrial relations. The

\footnotetext{
1) Department of Social Sciences and Philosophy, FIN-40014 University of Jyväskylä, Finland.

E-mail: tomi.oinas@jyu.fi
} 
presumption is that the political and historical compromises on industrial relations and production systems are nation specific (Gallie 2007a; Hult and Svallfors 2002) together with nationally varying societal welfare institutions such as family systems, educational systems, and security systems (Bosch et al. 2007; Davoine et al. 2008; Esping-Andersen 1990; 1999; Lewis 1992; Pascall and Kwak 2005).

In previous comparative studies, the Nordic countries have proven to be distinctive from other European countries in terms of the quality of their work life. Workers in Nordic countries report a higher quality of work tasks and better opportunities for participation in decision-making compared with other European countries (Gallie 2003). Moreover, Nordic countries seem to score high in self-development opportunities and learning at work (Green 2006; Parent-Thirion et al. 2007). The higher quality of work in Nordic countries is an interesting but also an ambiguous phenomenon.

A growing amount of comparative research literature is trying to discern differences between countries' institutional patterns and cultural norms in mediating the pressures of global capitalism. The presumption is that there are differences between national political and historical compromises on industrial relations and production systems. National industrial relation systems define, for example, to what extent work conditions are regulated by industry-wide collective bargaining, or by enterprise-level negotiations (Bosch et al. 2007; Burgoon and Raess 2009).

Gallie (2007) distinguishes two forms of argument that have been considered powerful in explaining institutional country differences. The first one classifies country groups according to their production regimes and the second in terms of their employment regimes. These two rivaling approaches can be used to provide a macro-level explanation for high job quality in Nordic countries.

The production regime theory derives from the corporatism tradition; however, the focus is mostly on the company level. The theory emphasizes companies as actors in the markets and in the institutional setting in which the companies operate. The institutional setting combines interrelations among educational and training systems, industrial relations systems, national innovation systems as well as corporate governance and the financial system (Soskice 1999; 2005). This approach differentiates between coordinated market economies (CMEs) in which competitiveness is sought through an upgrading of workforce skills, while safeguarding a high employee control over the work process, and the liberal market economies (LMEs), depending upon general skills acquired through the school system and coordinating their activities mainly in terms of hierarchies and competitive market arrangements. The use of relatively low-skilled workforce is based on tighter managerial control, resulting in the intensification of work. Generally, CMEs are characterized by a higher degree of state-led non-market coordination than LMEs, where a greater role is given to competitive market arrangements (Gallie 2007; Olsen et al. 2010).

While production regime theory emphasizes the centrality of the role of employers, the theory of employment regimes seeks variation in the power resources, i.e., the relative organizational capacity of employers and employees. Here, the state has an important role as a mediating actor between employers and labor. Employment regime theory assumes three principal types of employment and industrial policies that vary according to the scope of their employment rights and regulation. An inclusive employment regime is designed to provide (common) employment rights as widely as possible among populations of working age. Dualist employment regimes concentrate on 
providing strong rights to the skilled, long-term, core workforce at the expense of the peripheral workforce with low-security jobs. At the other end of the continuum is the market employment regime that emphasizes minimal employment regulation and relies on well-functioning market adjustment to create high employment levels. The role of labor in decision-making is restricted and institutional controls are seen as negative rigidities. Gallie $(2007,17)$ concludes that these three employment systems differ in relatively systematic ways in terms of the involvement of organized labor, principles underlying employment policy and welfare protection, the role of the public sector, and the salience quality of working life programs.

The Nordic countries are considered typical examples of CMEs or inclusive employment regime with universalized employment protection, in which organized labor has a strongly institutionalized position. The tradition of "quality of working life" programs has placed a strong emphasis on enriching the content of tasks, increasing employee discretion over how to carry out their jobs, and facilitating greater employee decisionmaking in organizational matters. Thus, if the quality of working life programs has had an effect, it is mainly with respect to the dimensions of task discretion and participation (Gallie 2003; Gustavsen 2007). And indeed, the Nordic country cluster scores high in terms of job quality in most international comparisons (Davoine et al. 2008; Gallie 2003; Hartikainen et al. 2010; Johnson et al. 2009; Kerkhofs et al. 2008; Lorenz and Valeyre 2005; Parent-Thirion et al. 2007; Tangian 2007; Wallace et al. 2007).

In contrast, Britain and Ireland are often defined as an example of LMEs or market employment system that is characterized by limited employee decision-making in work processes, tighter managerial control, and a higher intensity of work. However, recent studies point to clear differences between the UK and Ireland and question the validity of grouping them into the same regime (e.g., Gallie 2011). Traditionally, the sharpest distinction is drawn between "coordinated" Nordic and "liberal" Britain (Gallie 2007a).

Continental countries, such as Germany, are often categorized into the CMEs together with Nordic countries, or as an example of a dualist market economy. The Nordic and Continental coordinated societies were seen as having originally been distinct, with the Nordic countries representing a centralized egalitarian model of coordination and the Continental countries a flexibly coordinated model based upon industrial sector coordination. But the two forms were thought to have converged over time into a single flexibly coordinated model (Gallie 2011). In welfare regimes, continental countries like Germany, France, and Austria form an independent "corporatist" regime. In the enlarged EU, Continental countries often represent the job quality "average" (EC 2008).

Southern European countries are not easy to position in production or employment categories; Esping-Andersen originally considered them (immature) variants of the Continental model, but an extension to the southern regime has been proposed by Ferrera (1996). Southern countries are characterized by weak vocational training and early school leavers and medium levels of union centralization, and although they do have high levels of protection for core employees (Davoine et al. 2008), job quality appears lower than in other old EU member states. Employees have fewer opportunities for skill development and influencing their daily tasks and have a lower satisfaction with their jobs and work-life balance (EC 2008; Peña-Casas and Pochet 2009).

The production regime theory postulates that CMEs typically make extensive use of labor with high industry-specific or firm-specific skills. Consequently, they depend on 
education and training systems that are able to provide workers with such skills. In contrast, LMEs draw on general skills, which reduce company investments in training that in fluid labor markets can be utilized by other firms (Hall and Soskice 2001). Following this hypothesis, coordinated regimes would foster higher and more specialized skills. The differences in skill systems between CMEs and LMEs are likely to affect dimensions of job quality such as autonomy, opportunities of learning, and other forms of skill acquisition. Based on earlier studies, we expect that coordinated and inclusive regimes will score higher in particular in workers' task discretion or autonomy. If there are differences between CMEs and LMEs in the production systems and in the skill orientation of employers and employees, we should find higher levels of task and skill discretion in the Nordic countries.

When dismissal is made difficult by law, or by trade union procedures, this may reduce the management's ability to use the dismissal threat as a means of obtaining more effort from their workforce. Therefore, employment protection legislation and the level of unionization could be expected to be negatively related to level of work intensity. Work intensity is expected to be at a higher level in countries belonging to LMEs or market employment regime, namely the UK, which are characterized by liberal policy orientation to employment regulation, tighter management control, and weaker trade unions (Gallie 2005; Green and McIntosh 2001; Olsen et al. 2010).

According to institutional explanations, country differences would be expected to persist over time since institutional effects at national level are stronger than the "homogenization" effect of increased international competition and technological change (Olsen et al. 2010). Following Gallie (2011), we can expect the Nordic societies, which are closer to the inclusive employment regime model, to remain distinct in terms of the quality of work from the Continental societies, which are closest in their pattern of employment regulation to the dualistic regime model.

The objective of this study is to investigate whether Nordic countries have retained their advantageous position concerning job quality compared with other EU countries by 2010. Our article contributes to previous research on several points. First, we use a series of representative surveys with identical measure on job quality expanding over 15 years for all EU15 countries, including recent data on 2010. Second, instead of merely comparing country-level averages descriptively, we formally test the relative position of Nordic countries controlling for differences in compositional factors (cp. Eurofound 2012). Third, we classify countries according to theories of production and employment regimes, but all of our analyses are conducted on individual countries, not regimes. This enables us to examine how homogenous various regimes actually are when considering job quality.

\section{Dimensions of job quality}

A central methodological choice in assessing job quality is to decide whether to use a multidimensional approach with a variety of measures or to ask job holders to provide a general or global assessment of their job (Dahl et al. 2009; Kalleberg and Vaisey 2005). This study follows the tradition of the multidimensional approach to job quality. We employ measures of job quality that have been widely supported in recent literature (Dahl et al. 2009; Gallie 2007a; Green 2006; Olsen et al. 2010). The dimensions included are skills, autonomy, and work effort. 


\section{Skills}

The possibilities to develop and use skills at work are thought to be central for job quality as they create greater opportunities for internal or external professional mobility, and for finding a new job in case of dismissal, thus increasing the general employability (Employment in Europe 2008). In addition, many developed Western countries have started to emphasize that since they cannot compete with developing countries in mass production, their economic sustainability depends upon production quality, high skills, and creativity (Gallie 2007a). Empirical research shows that in industrialized countries, job requirements, educational levels, and qualifications for work have been rising (Feldstead et al. 2007; Lehto and Sutela 2005; Tåhlin 2007). But if we consider employees' subjective perceptions of the quality of job tasks, a different picture emerges. Opportunities for using and developing skills at work have been on a downward slope in many European countries (Peña-Casas and Pochet 2009), especially in Britain (Feldstead et al. 2007). There are also tendencies toward the polarization of skills and the mismatch of job requirements and the qualifications of job holders (Green 2006).

There are some theoretical arguments in favor of societal differences in production systems that would differentiate economies according to their emphasis on policies regarding improvement of the quality of working life while creating work conditions that are conducive to skill development (Gallie 2007). Compared with LMEs, the CMEs, like the Nordic Scandinavian countries and Germany, place a stronger emphasis on skill development and quality of production. Presumably in these countries employees attach particular importance to the intrinsic characteristics of work (Gallie 2007).

\section{Task discretion}

Autonomy is the extent to which workers can influence their work duties, requirements, and organization. It also has a central role in the sociology of work as it is closely linked to work effort and skills. Autonomy at work or task discretion and the level of a person's skill correlate strongly. However, the possession of skills and the use of skills do not necessarily guarantee a high degree of autonomy (Dahl et al. 2009). Together with work demands, the autonomy aspect forms the core of the psychosocial models of workplace well-being; a low latitude for decision-making coupled with high demands at work is a combination that potentially increases stress levels (Karasek and Theorell 1990). Loss of employee discretion has also been found to be detrimental to work satisfaction and subjective well-being at work (Green 2006).

Recent studies are ambiguous on the development of autonomy. Contrary to expectations, opportunities for influencing one's job have been found to be declining in most of the EU (Eurofound 2012), particularly in Britain (Feldstead et al. 2007; Gallie et al. 2004; Green and Mostafa 2012) and Germany (Green and Tsitsianis 2005; Peña-Casas and Pochet 2009). However, contrasting results have been found in the Nordic countries where modest increases in task discretion have been reported (Johnson et al. 2009; Lehto and Sutela 2005; Peña-Casas and Pochet 2009).

Some evidence that demonstrates that national employment systems have an influence on worker autonomy has been found. Nordic countries have been proved to have relatively high levels of employee discretion. This is explained by Nordic countries 
having skill-oriented employment systems, which offer, but also require, large employee responsibility and the capability to autonomously solve problems (Dahl et al. 2009; Gallie 2007b). Employee discretion varies according to managerial cultures. The quality of work-life policies adopted from the 1970s onward in Sweden-and to a lesser extent in other Nordic countries-included efforts to redesign jobs in order to enrich them (Green 2006).

\section{Work intensity}

Growing work-related pressures as a threat to worker well-being have come to the fore of debates regarding the quality of work life. The use of new technology and the consequent heightened demand it makes of workers to keep up with skill requirements is seen as a factor that increases work pressure, especially in combination with worries over job security (Gallie 2005; Green 2006). Moreover, the shifts in the structure of the economy, specifically the growth of the service sector, have resulted in changes in the determinants of the pace of work. Industrial constraints, for instance, the pace of work determined by the automatic speed of a machine, have been replaced by direct market constraints, such as direct demands from people (Parent-Thirion et al. 2007). This phenomenon, termed work intensification, which has its roots in effort-biased technological and organizational changes (Green 2006), is a critical factor behind changes in overall job satisfaction.

For Green $(2006,46)$, the concept of work effort "is the rate of physical and/or mental input to work tasks during the work day." The measurement of "input" in a person's work is ambiguous. Objective measures, such as work hours, do not necessarily catch the tempo of work during the time spent at work. Subjective measures, like perceptions about rising pressure or pace, are difficult to separate from more general feelings about the intensification of the pace of life. Reporting how busy one is can also be socially desirable (Gershuny 2005).

Several empirical studies show that despite falling hours of work, employees in the EU suffer from an increasing intensity of work (Burchell et al. 2009; Clark 2005; Green and McIntosh 2001; Green and Mostafa 2012). Green and McIntosh (2001) studied change in work effort from 1990 to 1995, reporting intensification in all 12 EU countries, although there were differences in the intensity of the change. More recent data reveal diverging developments: in most of the Southern European and Nordic countries, work effort seems to have risen gradually, but in countries such as the UK, Ireland, Germany, the Netherlands, and France, work effort has started to show a declining trend (Peña-Casas and Pochet 2009).

\section{Data and methods}

\section{Data}

The empirical analyses are based on the European Working Conditions Survey (EWCS) collected in 1995, 2000, 2005, and 2010 by The European Foundation for the Improvement of Living and Working Conditions (Eurofound). The statistical population of EWCS was persons in employment according to the Eurostat Labour Force Survey criteria. In 
each country, a multi-stage, stratified, and clustered design was used with a random walk procedure for the selection of respondents for the last stage. The target number of interviews in each country has been 1000 in all surveys except in the year 2000, when it was 1500 . However, there have been some exceptions from standard sample size. The sample size in Luxembourg has been lower (500-600) in surveys prior to 2010. In 2010, the UK, Italy, Germany, France, and Belgium had used increased sample size. The respondents were interviewed face-to-face in their homes outside normal working hours. The overall response rate was $44 \%$ in 2010 , although there was considerable variation in the participation rates in different countries. The dataset has been weighted to correct for non-responses. The post-stratification weight is constructed to match the European Labour Force Survey figures by using gender, age, occupation, sector, and region.

The data provide a unique insight into the evolution of the conditions of work and employment in the EU. The range of countries covered in the EWCS reflects the expansion of the EU. The first wave, in 1991, covered only 12 countries; the second wave in 1995 covered 15 countries; and the third wave from 2000 to 2001 onward covered all 27 current EU member states, plus Turkey (in 2002, 2005, and 2010), Norway and Croatia (in 2005 and 2010), Switzerland (in 2005), and Albania, Montenegro, Kosovo, and the former Yugoslav Republic of Macedonia in the most recent wave. The number of questions and issues covered in the survey has been expanded for each subsequent wave. However, the survey allows for comparison over time as it retains a core of key questions, and it also permits comparison across countries because it uses the same questionnaire everywhere (Eurofound 2012).

When analyzing trends in job quality, we have to take into account previously mentioned developments in the survey, namely the progressive inclusion of new countries and the more comprehensive set of measures for job quality that have been included as the survey has developed. Most of the variables measuring different dimensions of job quality were first introduced in the second wave, which makes the 1995 survey the earliest possible starting point for our analysis (Peña-Casas and Pochet 2009). In order to provide a long-term picture, while keeping a reasonably large number of countries and measures of job quality, we restrict our analyses to employees of the 15 member states of the EU prior to enlargement in $2004(n=61,457)$. When interpreting the results, one should bear in mind that they may also depend on the timing of the last data collection point, which corresponds with the economic depression of 2010 .

We classify the EU15 countries according to theories of production and employment regimes, but all of our analyses were conducted on individual countries, not regimes. This enables us to see whether countries inside these regimes are truly homogenous or not. The Nordic countries include Denmark, Finland, and Sweden. We excluded Norway from our analysis because it was included in the EWCS surveys only from 2005 onward. Liberal countries encompass the UK and Ireland. Recent studies point to clear differences between the UK and Ireland and question the validity of grouping them into the same regime (e.g., Gallie 2011). In our case, this poses no problems, since all analyses are conducted for individual countries. Belgium, Germany, France, Luxembourg, the Netherlands, and Austria are classified as belonging to the Continental regime. Finally, the Southern regime comprises Greece, Spain, Italy, and Portugal. This clustering of countries is widely used but also much criticized since it tends to mask the internal diversity in the groups. 


\section{Methods}

Comparing countries or regimes by use of only raw figures on dimensions of job quality is not satisfactory for the purpose of our analysis. Any observed difference can be partly explained by compositional differences between countries in occupational structure, sector, industry, etc. In order to take into account these compositional differences between countries, we use multivariate regression models to analyze country effects on dimensions of job quality separately for each survey year. Depending on the nature of the dependent job quality measure, we employ either linear or logistic regression models with country dummies as explanatory factors. Entering age, gender, occupation, sector, and industry dummies as covariates in the regression models allows us to compare differences in job quality between countries' net of structural differences. This strategy has been previously used in the analysis of country differences and trends in job quality (e.g., Gallie 2003; 2005; Green and McIntosh 2001; Green and Mostafa 2012).

There is, however, one drawback with this analysis strategy, namely the difficulty of selecting valid reference country to which other countries are compared. For example, Gallie (2003) used Belgium as the reference country and coefficients of country effects in his analysis indicate whether or not job quality in a particular country was of higher or lower quality than in Belgium. Whether or not Belgium is the most suitable country to compare others with can be questioned. However, by using different coding schemes for country effects, the problem of selecting a valid country as a reference could be avoided.

Thus, instead of a conventional simple or dummy coding, we use deviation contrast or effects coding. In effects coding, each country other than the excluded country is compared with the unweighted average of all groups. In case of logistic regression, it measures the deviation of the logit from each group from the unweighted average logit for the entire sample (Menard 2009; Wendorf 2004). Thus, effects coding enables us to formally test whether Nordic countries have indeed retained their advantageous position in job quality compared with other EU countries on average. In addition, by using this coding scheme, we are actually analyzing the relative position on Nordic countries regardless of the actual level of each measure of job quality. As in all coding schemes of categorical variables, one country has to be left out as a "reference." Contrary to standard dummy coding, in effects coding this category can be one we are least interested in. In our analysis, Ireland is left out because of its ambiguous position considering different regimes, i.e., whether or not it should be included in the Liberal regime together with the UK (e.g., Gallie 2011). Positive coefficients indicate better job quality than in EU15 on average, except for work intensity.

As noted above, some countries have had smaller or bigger sample sizes than the standard sample size of 1000 persons. Because differences in sample size affect the significance tests, we rescaled weights so that effective sample size is 1000 respondents in each country per survey year. This procedure makes the coefficients of country effects comparable between different survey years and countries.

\section{Measures of job quality}

To capture the level of skill requirements in job, an index summarizing the use of different cognitive skills was created. From the survey, we included three questions: whether 
or not a respondent's job involves solving unforeseen problems on their own, complex tasks, and the learning of new things. The skill index was formed by counting together how many different types of skill demands a respondent's job includes-the score ranges from 0 to 3 . Respondents were coded as working in high-skilled jobs, if their jobs included all the above-mentioned aspects of skill demands (skill index score 3 ).

The questionnaire included three indicators that ask a worker to describe their influence and control over their work process, i.e., task discretion. Respondents were asked whether or not they were able to choose or change the order of their tasks, the methods of work, and the speed or rate of work. A composite index was constructed by counting how many times the respondent answered "yes" to these questions (i.e., an indicator represents values as measured from a low of 0 to a high of 3). Employees that were able to influence all three aspects of autonomy in their work (a score of 3) were defined as having "high work discretion."

To describe the experiences of the intensity of the work, the respondents were asked to evaluate to what extent their job required "working at very high speed" and "working to tight deadlines." Response categories were $1=$ never to $7=$ all of the time. Together these two questions form an effort indicator with a range of 1 to 7 . The reliability of the scale was reasonably good, producing a Cronbach's alpha of 0.71 .

The unadjusted country levels of all three measures by survey year are represented in Appendix 1.

\section{Results}

\section{The level of job quality in 1995-2010}

\section{Skill requirements}

Table 1 shows the development of country differences regarding high skill level between 1995 and 2010 after adjusting for compositional effects, i.e., the characteristics of employees. Nordic countries indeed score above average on prevalence of high skill level in every survey, as would be expected from regime theories. However, Austria which is usually defined as belonging to the continental regime scores equally high as Nordic countries. The Liberal regime, i.e., the UK, also scored high in the 1990s on skill requirements, as did the Netherlands from the Continental regime. Interestingly, in 1995, the UK together with Finland and Sweden scored higher than Denmark in skill requirements. In 2010, Denmark, in contrast, differed from other Nordic countries due to its higher skill level. Countries belonging to the Southern regime have quite uniformly had lowest levels of skill requirements for the whole of the 1995 to 2010 period. This result clearly points to the existence of quite a homogenous Southern regime.

According to these results, there is clear indication of the existence of a distinct Nordic cluster with high skill level of employees. However, Austria is no different from this regime. In addition, the UK and the Netherlands from the Continental regime have lost somewhat their previously high skill level and are now at a lower skill level than the Nordic countries. On the whole, the Continental regime seems to be quite heterogenous when considering the skill level of employees. These results are somewhat in contrast to the expectations derived from production regime theories, i.e., that there is sharp 
Table I Country effects on skill requirements from logistic regression analysis!.

\begin{tabular}{|c|c|c|c|c|c|}
\hline \multicolumn{2}{|c|}{ Regime and country } & \multicolumn{4}{|c|}{ Survey year } \\
\hline & & 1995 & 2000 & 2005 & 2010 \\
\hline \multirow[t]{3}{*}{ Nordic } & Denmark & $0.21 * *$ & $0.55 * * *$ & $0.90 * * * *$ & $0.78 * * *$ \\
\hline & Finland & 0.60**** & $0.52 * * * *$ & 0.48***** & 0.36 **** \\
\hline & Sweden & $0.62 * * * *$ & $0.25 * * *$ & 0.34***** & $0.42 * * *$ \\
\hline \multirow[t]{6}{*}{ Continental } & Austria & 0.46 **** & $0.53 * * * *$ & $0.53^{*} * * *$ & $0.70 * * *$ \\
\hline & Belgium & $-0.43 * * * *$ & $-0.19 *$ & $-0.16^{*}$ & $-0.2 I^{* * *}$ \\
\hline & France & 0.07 & -0.08 & -0.12 & -0.37 **** \\
\hline & Germany & $0.17^{*}$ & $0.18^{*}$ & -0.03 & 0.12 \\
\hline & Luxembourg & -0.11 & $-0.15 *$ & -0.03 & 0.08 \\
\hline & The Netherlands & 0.25 **** & 0.39 **** & 0.34米米米 & -0.11 \\
\hline Liberal & United Kingdom & $0.69 * * * *$ & 0.35 **** & -0.09 & $0.24 * *$ \\
\hline \multirow[t]{4}{*}{ Southern } & Greece & $-0.84 * * *$ & $-0.82 * * * *$ & -0.59 ***** & -0.55 *** \\
\hline & Italy & $-0.40 * * * *$ & -0.56 ***** & $-0.53 * * * *$ & $-0.73 * * *$ \\
\hline & Portugal & $-0.49 * * * *$ & $-0.44 * * * *$ & $-\left.0.2\right|^{*} * *$ & $-0.17 *$ \\
\hline & Spain & $-0.7 \mid$ **** & -0.40 **** & $-0.64 * * * *$ & -0.52 *** \\
\hline \multicolumn{2}{|c|}{ Nagelkerke $R^{2}$} & 0.18 & 0.19 & 0.22 & 0.22 \\
\hline \multicolumn{2}{|l|}{ Weighted N } & | I,359 & 12,252 & $|2,0| 4$ & 12,094 \\
\hline
\end{tabular}

' Controlling for age, sex, occupation, sector, and industry.

The coefficients are deviations from the unweighted average logit of all countries (excluding Ireland)

Statistical significance: $* p<0.05, * * p<0.01$, ${ }^{*} * * p<0.001$.

distinction between LMEs and CMEs such as Nordic countries in skill formation systems (e.g., Gallie 2007a). By contrast, the Southern regime with its lower level of vocational training (Davoine et al. 2008) drags behind the rest of Europe in abilities to use skills.

\section{Task discretion}

After adjusting for differences in the structural characteristics of employees, we find no indication of distinct Nordic cluster with a high level of task discretion (Table 2). Denmark has had the highest levels of autonomy for the whole observation period, but Finland has caught up with Denmark during the last five years. In contrast, task discretion seems to be lower in Sweden, after a clear decline between the last two surveys. In 2000 and 2005, Sweden scored higher than Finland on task discretion. In addition to Sweden, there was a decline in task discretion in the Liberal regime, i.e., the UK. This result is in line with studies that have addressed opportunities to influence work and found that this has been in decline in the Liberal regime countries (Feldsted et al. 2007; Gallie et al. 2004). Some countries belonging to the Continental cluster also score above average in task discretion, namely the Netherlands, Belgium, and recently also Luxembourg. 
Table 2 Country effects on task discretion from logistic regression analysis!.

\begin{tabular}{|c|c|c|c|c|c|}
\hline \multicolumn{2}{|c|}{ Regime and country } & \multicolumn{4}{|c|}{ Survey year } \\
\hline & & \multirow{2}{*}{$\frac{1995}{0.61 * * * * 6}$} & \multirow{2}{*}{$\frac{2000}{0.69 * * * * 1}$} & \multirow{2}{*}{$\frac{2005}{0.73 * * * *}$} & \multirow{2}{*}{$\frac{2010}{0.84 * * * *}$} \\
\hline Nordic & Denmark & & & & \\
\hline & Finland & 0.11 & 0.09 & 0.12 & 0.66 **** \\
\hline & Sweden & 0.07 & 0.21 *** & $0.29 * * * *$ & $-0.14 *$ \\
\hline \multirow[t]{6}{*}{ Continental } & Austria & $-0.23 * *$ & -0.03 & $-0.19 *$ & -0.46 ***** \\
\hline & Belgium & $0.22 * *$ & 0.01 & $0.32 * * * *$ & 0.11 \\
\hline & France & $0.24 * *$ & 0.04 & 0.12 & $-0.23 * *$ \\
\hline & Germany & 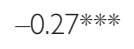 & -0.05 & -0.35 ***** & $-0.16 *$ \\
\hline & Luxembourg & -0.06 & $-0.15 *$ & 0.10 & $0.18 * *$ \\
\hline & The Netherlands & $0.42 * * * *$ & $0.59 * * *$ & $0.20 * *$ & $0.17 *$ \\
\hline Liberal & United Kingdom & $0.29 * * * *$ & 0.12 & 0.05 & -0.04 \\
\hline \multirow[t]{4}{*}{ Southern } & Greece & $-0.7 \mid$ *****十 & $-0.76 * * * *$ & $-0.59 * * * *$ & $-0.6 \mid * * * *$ \\
\hline & Italy & $-0.40 * * * *$ & $-0.18 *$ & $-0.42 * * * *$ & $0.29 * * * *$ \\
\hline & Portugal & 0.03 & -0.11 & $-0.17 *$ & -0.06 \\
\hline & Spain & $-0.3 \mid * * * *$ & $-0.30 * * * *$ & $-0.30 * * *$ & $-0.25 * * * *$ \\
\hline \multicolumn{2}{|c|}{ Nagelkerke $R^{2}$} & 0.09 & 0.10 & 0.11 & 0.11 \\
\hline \multicolumn{2}{|l|}{ Weighted N } & 11,358 & $|2,25|$ & $12,0 \mid 4$ & 12,095 \\
\hline
\end{tabular}

' Controlling for age, sex, occupation, sector, and industry.

The coefficients are deviations from the unweighted average logit of all countries (excluding Ireland).

Statistical significance: ${ }^{*} p<0.05, * * p<0.01$, ${ }^{*} * * p<0.001$.

However, there is considerable fluctuation between survey years in countries' relative position in task discretion. Presently there seems to be clear polarization between countries with regard to worker autonomy; Denmark and Finland form a high autonomy cluster and the rest of the EU15 countries are far behind. However, some of the changes between the last two waves of the survey are very dramatic and cast some doubts on the reliability of the data. Especially the sharply contrasting trend in Finland and Sweden needs more thorough investigation. ${ }^{1}$ The same holds also for the surprising increase in task discretion in Italy. In addition, combining task discretion and skills to one index masks clear differences between countries in these dimensions (see Green and Mostafa 2012).

\section{Work intensity}

In general, high work intensity has been a more common feature in the Nordic countries, but only in Finland and Sweden (Table 3). In Denmark, work intensity has been no higher than the average European level. In contrast, Austria and Germany have had 
Table 3 Country effects on work intensity from OLS regression analysis!.

\begin{tabular}{|c|c|c|c|c|c|}
\hline \multicolumn{2}{|c|}{ Regime and country } & \multicolumn{4}{|c|}{ Survey year } \\
\hline & & 1995 & 2000 & 2005 & 2010 \\
\hline \multirow[t]{3}{*}{ Nordic } & Denmark & 0.10 & -0.08 & 0.5 I $* * * * *$ & -0.05 \\
\hline & Finland & 0.81 ***** & $0.55 * * *$ & 0.57 ***** & $0.29 * * * *$ \\
\hline & Sweden & $0.44 * * * * *$ & $0.78 * * * *$ & $0.57 * * * * *$ & 0.42 ***** \\
\hline \multirow[t]{6}{*}{ Continental } & Austria & $0.78 * * * *$ & $0.20 * *$ & $0.39 * * *$ & $0.23 * * * *$ \\
\hline & Belgium & $-0.59 * * * *$ & $-0.36 * * *$ & $-0.32 * * * *$ & $-0.22 * *$ \\
\hline & France & $-0.27 * * * *$ & $-0.18 * *$ & -0.36 **** & -0.09 \\
\hline & Germany & $0.30 * * * *$ & $0.14 *$ & $0.28 * * * *$ & 0.35 ***** \\
\hline & Luxembourg & $-0.62 * * * *$ & $-0.25 * * *$ & $-0.29 * * * *$ & $-0.13^{*}$ \\
\hline & The Netherlands & $0.12 *$ & 0.31 ***** & $-0.25 * * * *$ & -0.10 \\
\hline Liberal & United Kingdom & $0.42 * * * *$ & 0.12 & $-0.18 * *$ & 0.00 \\
\hline \multirow[t]{4}{*}{ Southern } & Greece & 0.12 & $0.16 *$ & 0.46 **** & 0.43米米 \\
\hline & Italy & $-0.62 * * *$ & $-0.15^{*}$ & -0.01 & $-0.15^{*}$ \\
\hline & Portugal & $-0.32 * * *$ & $-0.73 * * *$ & $-\left.0.6\right|^{* * * *}$ & $-0.83^{*} * * *$ \\
\hline & Spain & -0.64 ****** & -0.46 ***** & $-0.24 * * *$ & -0.36 ***** \\
\hline \multicolumn{2}{|l|}{$R^{2}$} & 0.09 & 0.06 & 0.07 & 0.06 \\
\hline \multicolumn{2}{|l|}{ Weighted N } & | |,683 & ||$, 4 \mid 5$ & 11,960 & 10,979 \\
\hline
\end{tabular}

'Controlling for age, sex, occupation, sector, and industry.

The coefficients are deviations from the unweighted mean of all countries (excluding Ireland).

Statistical significance: $* p<0.05, * * p<0.01$, ${ }^{* * *} p<<0.001$.

work intensity at level comparable to Sweden and Finland. Work intensity has been the lowest in countries belonging to the Southern regime for the whole period. Also Belgium, France, and Luxembourg have had low levels of work intensity. Interestingly, work intensity relative to the average level has been steadily increasing in Greece for the whole observation period. In 2010, work intensity in Greece was as high as in Germany or Sweden. Contrary to the theory of production regimes, work intensity is higher in Nordic countries with higher employment protection and stronger unions. In contrast, work intensity was no different from the European average in the UK, which is considered to be a typical example of liberal policy orientation to employment regulation, tighter management control, and weaker trade unions.

Again, there is no clear indication of distinct Nordic cluster in the level of work intensity. Despite some contrasting trends, there have been only minor changes in the relative position of the countries or regimes regarding the level of work intensity. However, there are again surprising changes in some countries' relative positions between different surveys. The most obvious example of this is the sudden peak of work intensity in Denmark in 2005. Again, this finding casts doubts on the reliability of the EWCS data on some countries and variables. 


\section{Summary and conclusions}

Job quality is a multidimensional phenomenon, which touches on a broad set of individual job and workers' characteristics. In this study, we follow the tradition of the multidimensional approach to job quality. Here we look more closely at some key indicators of job quality, namely skill requirements, task discretion, and work intensity. Previous empirical research has pointed out that Nordic countries distinguish from the rest of the Europe in terms of job quality. Comparative research literature tries to explain the distinctiveness of Scandinavian countries with diverse sets of institutional frameworks such as the political and historical compromises on industrial relations together with societal welfare institutions such as family, educational, and security systems. On the other hand, it has been debated whether, in the longer run, the Nordic welfare state is able to insulate workers from the effects of globalization. The aim of this article was to investigate whether the Nordic countries have retained their advantageous position concerning job quality compared with other EU countries by 2010. In general, our results speak in favor of societal effects on job quality even after controlling for differences in compositional factors. These findings are in contrast to Smith et al. (2008), who conclude that gender and occupational status along with job characteristics like working time and economic sector are more significant factors than national or country-specific models for an individual's job quality.

Our results corroborate the findings of a great deal of previous research showing that Nordic countries have the highest proportion of workers whose job includes creative elements. As expected by Gallie (2011), the Nordic societies, which are closer to the inclusive employment regime model, remain relatively distinct in terms of the quality of work from the Continental societies, which are closest in their pattern of employment regulation to the dualistic regime model. The "learning" forms of work organization, drawing on employees' capacity for continuous learning and problem solving, are found to be widely diffused in the Nordic countries. Although we controlled for some compositional factors, the differences may derive from different degrees to which national producers are positioned on the high-technology or high-quality end of product markets (Lorenz and Valeyre 2005). Our results indicate also substantial variation between country clusters in job quality.

However, we found clear differences between Nordic countries for both current levels and long-term trends with regard to various dimensions of job quality. Denmark appears to stand out from the rest of Europe, including other Nordic countries, with very high levels of job quality. In this regard, Southern European countries represent the lower end of the job quality. However, the other EU Nordic countries, i.e., Sweden and Finland, are, in many respects, not different from some of the continental countries, especially Austria and the Liberal UK. These results are basically in line with earlier studies indicating that liberal economies are converging with coordinated economies, such as the Nordic countries, on some dimensions of job quality (Davoine et al. 2008; Olsen et al. 2010; Peña-Casas and Pochet 2009). These convergences are due to both the degradation of job quality in some Nordic countries and an improvement in the Liberal regime (cp. Olsen et al. 2010). Our findings are also in line with Gallie (2011) and challenge the existence of separate Liberal cluster including Ireland. However, different measures give quite a contrasting picture of country differences in job quality.

Following hypotheses derived from production regime theory, CMEs would foster and require higher skills compared with LMEs. Our results showed, however, that the 
skill requirements are at a lower level in "coordinated Germany" compared with "liberal UK." Interestingly, the analysis showed that the assumptions relating to high levels of task discretion in Nordic countries and respectively low levels in liberal cluster are partly misleading. The level of task discretion has been and stayed at a very high level in Denmark, but Finland and Sweden are not so different from liberal and some continental countries. The analysis of task discretion shows a negative trend also in some of the Continental countries. This leads us to question the dominance of post-bureaucratic forms of work organization. The observed stagnation, or even reduction, in task discretion could be attributed to new and subtle forms of work control and the rediscovery of Fordist principles, resulting in the loss of employee autonomy. New "neo-Fordist" managerial strategies might lead to stricter supervisory, peer, and technical control and thus result in a loss of employee task discretion (Gallie et al. 2004) and increased stress (Kalleberg et al. 2009; White et al. 2003). Therefore, managerial cultures and ways of controlling the work process should be emphasized in further research.

Based on regime theories, we expected that work intensity would be at a higher level in countries belonging to LMEs or market employment regime, namely the UK, which are characterized by liberal policy orientation to employment regulation, tighter management control, and weaker trade unions. This was not the case, however. In contrast, the levels of work intensity were highest in the Nordic countries, excluding Denmark. In the UK, the work intensity was near the European average. High level of unionization or employment protection in Sweden and Finland has not resulted in reduced work intensity, quite the contrary. Clearly, neither employment nor production regime theory is capable of explaining persisting differences between European countries in work intensity. In contrast, results to some extent support the argument that higher skill levels and grater job control are actually associated with high work intensity (see Gallie 2005). The need to learn new tasks and the increased responsibilities of employees in Nordic countries are coupled with more work intensity. However, an interesting question is what causes the sharp difference in work intensity between employees in Denmark and other Nordic countries.

The empirical findings in this article show that within Europe there are variations between and within regimes with respect to levels of job quality. Thus, the implications of the economic processes are not likely to be similar across capitalist societies. The analysis shows that current assumptions about the impact of "globalization" on job quality and the decline in the significance of the nation state may be exaggerated. The comparative approach with crude country clusters tends to mask internal variation within clusters, and indeed, there is a lot of variation within each regime.

All in all, our central finding is that the Nordic countries have retained their distinctive position relative to all other country groups. As stated by Gallie (2011), the pursuit of strong policies of employee welfare, supported by a high degree of institutionalization of joint regulation both at the national level and in the workplace, is the most plausible explanation of the sources of their comparative advantage. However, maintaining a distinct quality of work life in Northern European countries is not self-evident. National institutional structures, such as education system and collective labor agreements that have supported the work-life developments, are themselves subjected to change pressures. For example, in Sweden, researchers have pointed out that a weakening welfare state is no longer able to produce positive effects to work life (e.g., Huzzard 2003). Hence, there is need for continuous attention to work-life development and research in Nordic countries. 
Appendix I Level of job quality indicators by country and survey year (EWCS)

\begin{tabular}{|c|c|c|c|c|c|c|}
\hline \multirow[t]{2}{*}{ Measure } & \multirow[t]{2}{*}{ Regime } & \multirow[t]{2}{*}{ Country } & \multicolumn{4}{|c|}{ Survey year } \\
\hline & & & 1995 & 2000 & 2005 & 2010 \\
\hline \multirow{15}{*}{ 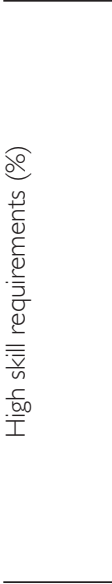 } & Nordic & Denmark & $52 \%$ & $56 \%$ & $68 \%$ & $66 \%$ \\
\hline & & Finland & $64 \%$ & $60 \%$ & $63 \%$ & $57 \%$ \\
\hline & & Sweden & $63 \%$ & $51 \%$ & $61 \%$ & $60 \%$ \\
\hline & Continental & Austria & $55 \%$ & $58 \%$ & $62 \%$ & $61 \%$ \\
\hline & & Belgium & $40 \%$ & $41 \%$ & $46 \%$ & $46 \%$ \\
\hline & & France & $48 \%$ & $43 \%$ & $44 \%$ & $42 \%$ \\
\hline & & Germany & $53 \%$ & $49 \%$ & $50 \%$ & $52 \%$ \\
\hline & & Luxembourg & $45 \%$ & $42 \%$ & $54 \%$ & $56 \%$ \\
\hline & & The Netherlands & $54 \%$ & $56 \%$ & $60 \%$ & $50 \%$ \\
\hline & Liberal & United Kingdom & $64 \%$ & $53 \%$ & $48 \%$ & $53 \%$ \\
\hline & & Ireland & $43 \%$ & $44 \%$ & $48 \%$ & $48 \%$ \\
\hline & Southern & Greece & $28 \%$ & $26 \%$ & $38 \%$ & $36 \%$ \\
\hline & & Italy & $38 \%$ & $34 \%$ & $40 \%$ & $34 \%$ \\
\hline & & Portugal & $30 \%$ & $29 \%$ & $41 \%$ & $39 \%$ \\
\hline & & Spain & $30 \%$ & $35 \%$ & $32 \%$ & $36 \%$ \\
\hline \multirow{15}{*}{ 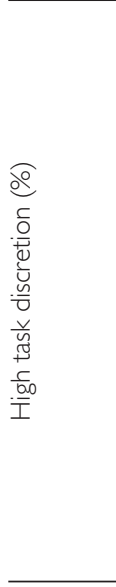 } & Nordic & Denmark & $65 \%$ & $65 \%$ & $66 \%$ & $70 \%$ \\
\hline & & Finland & $57 \%$ & $54 \%$ & $53 \%$ & $66 \%$ \\
\hline & & Sweden & $56 \%$ & $56 \%$ & $58 \%$ & $50 \%$ \\
\hline & Continental & Austria & $46 \%$ & $50 \%$ & $49 \%$ & $41 \%$ \\
\hline & & Belgium & $62 \%$ & $54 \%$ & $59 \%$ & $56 \%$ \\
\hline & & France & $58 \%$ & $51 \%$ & $54 \%$ & $48 \%$ \\
\hline & & Germany & $46 \%$ & $50 \%$ & $42 \%$ & $46 \%$ \\
\hline & & Luxembourg & $52 \%$ & $47 \%$ & $55 \%$ & $58 \%$ \\
\hline & & The Netherlands & $64 \%$ & $65 \%$ & $58 \%$ & $58 \%$ \\
\hline & Liberal & United Kingdom & $60 \%$ & $55 \%$ & $53 \%$ & $55 \%$ \\
\hline & & Ireland & $56 \%$ & $50 \%$ & $57 \%$ & $49 \%$ \\
\hline & Southern & Greece & $52 \%$ & $46 \%$ & $46 \%$ & $51 \%$ \\
\hline & & |taly & $53 \%$ & $51 \%$ & $52 \%$ & $60 \%$ \\
\hline & & Portugal & $58 \%$ & $49 \%$ & $48 \%$ & $52 \%$ \\
\hline & & Spain & $50 \%$ & $46 \%$ & $44 \%$ & $48 \%$ \\
\hline \multirow{15}{*}{ 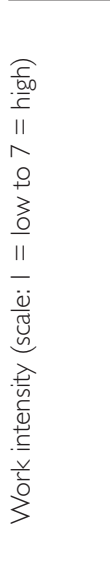 } & Nordic & Denmark & 3.5 & 3.4 & 4.2 & 3.5 \\
\hline & & Finland & 4.1 & 4.0 & 4.2 & 3.9 \\
\hline & & Sweden & 3.8 & 4.2 & 4.2 & 4.0 \\
\hline & Continental & Austria & 4.3 & 3.8 & 4.1 & 3.8 \\
\hline & & Belgium & 2.9 & 3.2 & 3.6 & 3.4 \\
\hline & & France & 3.2 & 3.4 & 3.3 & 3.6 \\
\hline & & Germany & 3.7 & 3.7 & 4.0 & 3.9 \\
\hline & & Luxembourg & 2.7 & 3.2 & 3.4 & 3.4 \\
\hline & & The Netherlands & 3.6 & 3.8 & 3.4 & 3.5 \\
\hline & Liberal & United Kingdom & 3.9 & 3.7 & 3.5 & 3.5 \\
\hline & & Ireland & 3.2 & 3.5 & 3.2 & 3.8 \\
\hline & Southern & Greece & 3.5 & 3.7 & 4.2 & 4.0 \\
\hline & & Italy & 2.9 & 3.4 & 3.6 & 3.5 \\
\hline & & Portugal & 3.1 & 2.8 & 3.2 & 2.7 \\
\hline & & Spain & 2.9 & 3.0 & 3.6 & 3.3 \\
\hline
\end{tabular}




\section{References}

Bosch, G., Rubery, J., \& Lehndorff, S. (2007). European employment models under pressure to change. International Labour Review, 146(3-4): 253-277.

Burchell, B., Cartron, D., Csizmadia, P., Delcampe, S., Gollac, M., Illésy, M., et al. (2009). Working Conditions in the European Union: Working Time and Work Intensity (European Foundation for the Improvement of Living and Working Conditions). Luxembourg: Office for Official Publications of the European Communities.

Burgoon, B., \& Raess, D. (2009). Globalization and working time: Working hours and flexibility in Germany. Politics \& Society, 37(4): 554-575.

Clark, A. (2005). Your money or your life: Changing job quality in OECD countries. British Journal of Industrial Relations, 43(3): 377-400.

Dahl, S.-Å., Nesheim, T., \& Olsen, K. (2009). Quality of work-concept and measurement. In: Guillén, A. M., \& Dahl, S.-Å. (eds.) Quality of Work in the European Union. Concepts, Data and Debates from a Transnational Perspective (19-40). Brussels: Peter Lang.

Davoine, L., Ehrel, C., \& Guergoat-Lariviere, M. (2008). Monitoring quality in work: European employment strategy indicators and beyond. International Labour Review, 147(2-3): 163-198.

Esping-Andersen, G. (1990). Three Worlds of the Welfare Capitalism. Oxford, Polity Press.

Esping-Andersen, G. (1999). Social foundations of postindustrial economies. Oxford: Oxford University Press.

Eurofound (2012). Fifth European Working Conditions Survey, Publications Office of the European Union, Luxembourg.

European Commission (2008). Employment in Europe 2008. EC: Luxembourg.

Feldstead, A., Gallie, D., Green, F., \& Zhou, Y. (2007) Skills at Work, 1986 to 2006. Universities of Oxford and Cardiff: ESRC Centre on Skills, Knowledge and Organisational performance.

Ferrera, M. (1996). The "Southern model” of welfare in social Europe. Journal of European Social Policy, 6(1): 17-37.

Gallie, D. (2003). The quality of working life: Is Scandinavia different? European Sociological Review, 19(1): 61-79.

Gallie, D. (2005). Work pressure in Europe 1996-2001: Trends and determinants. British Journal of Industrial Relations, 43(3): 351-375.

Gallie, D. (2007a). Production regimes, employment regimes and the quality of work. In: Gallie, D. (ed.). Employment Regimes and the Quality of Work (pp. 1-33). New York: Oxford University Press.

Gallie, D. (2007b). Production regimes and the quality of employment in Europe. Annual Review of Sociology, 33: 85-104.

Gallie, D. (2007c). Welfare regimes, employment systems and job preference orientations. European Sociological Review, 23(3): 279-293.

Gallie, D. (2011) Production Regimes, Employee Job Control and Skill Development, published by the Centre for Learning and Life Chances in Knowledge Economies and Societies.

Gallie, D., Feldstead, A., \& Green, F. (2004). Changing patterns of task discretion in Britain. Work, Employment \& Society, 18: 243-266.

Gershuny, J. (2005). Busyness as the badge of honor for the new superordinate working class. Social Research, 72(2): 287-314.

Green, F. (2006). Demanding Work. The Paradox of Job Quality in the Affluent Economy. Princeton and Oxford: Princeton University Press.

Green, F., \& McIntosh, S. (2001). The intensification of work in Europe. Labour Economics, 8: 291-308. 
Green, F., \& Mostafa, T. (2012). Trends in Job Quality in Europe. Publications Office of the European Union, Luxembourg.

Green, F., \& Tsitsianis, N. (2005). An investigation of national trends in job satisfaction in Britain and Germany. British Journal of Industrial Relations, 43(3): 401-429.

Gustavsen, B. (2007). Work organization and the Scandinavian model. Economic and Industrial Democracy, 28: 650-673.

Hall, P. A., \& Soskice, D. (eds.) (2001) Varieties of Capitalism: The Institutional Foundations of Comparative Advantage. Oxford: Oxford University Press.

Hartikainen, A., Anttila, T., Oinas, T., \& Nätti, J. (2010). Is Finland different? Job quality among Finnish and European employees. Research on Finnish Society, 3: 29-41.

Hult, C., and Svallfors, S. (2002). Production regimes and work orientations: A comparison of six western countries. European Sociological Review, 18: 315-331.

Huzzard, T. (2003). The Convergence of the Quality of Working Life and Competitiveness: A Current Swedish Literature Review. Work Life in Transition. 2003: 9. Stockholm. National Institute for Working Life.

Johnson, P., Wood, G., Brewster, C., \& Brookes, M. (2009). The rise of post-bureaucracy: Theorists' fancy or organisational praxis? International Sociology, 24(1): 37-61.

Kalleberg, A., \& Vaisey, S. (2005). Pathways to a good job: Perceived work quality of the machinists in North America. British Journal of Industrial Relations, 43(3): 431-454.

Kalleberg, A., Nesheim, T. \& Olsen, K. (2009). Is Participation Good or Bad for the Workers? Effects of Autonomy, Consultation, and Teamwork on Stress among Workers in Norway. Acta Sociologica, 52(2): 99-116.

Karasek, R., \& Theorell, T. (1990). Healthy Work: Stress Productivity and the Reconstruction of Working Life. New York: Basic Books.

Kerkhofs, M., Chung, H., \& Ester, P. (2008). Working time flexibility across Europe: A typology using firm-level data. Industrial Relations Journal, 39(6): 569-585.

Lehto, A.-M., \& Sutela, H. (2005). Threats and Opportunities: Findings of Finnish Quality of Working life Surveys 1977-2003. Helsinki: Statistics Finland.

Lewis, J. (1992). Gender and the development of welfare regimes. Journal of European Social Policy, 2(3): 159-173.

Lorenz, E., \& Valeyre, A. (2005). Organisational innovation, human resource management and labour market structure: A comparison of the EU-15. Journal of Industrial Relations, 47(4): 434-442.

Menard, S. (2009). Logistic Regression: From Introductory to Advanced Concepts and Applications. Thousand Oaks, CA: Sage.

Olsen, K., Kalleberg, A., \& Nesheim, T. (2010). Perceived job quality in the United States, Great Britain, Norway and West Germany 1989-2005. European Journal of Industrial Relations, 16(3): 221-240.

Parent-Thirion, A., Fernández Macías, E., Hurley, J., \& Vermeylen, G. (2007). Fourth European Working Conditions Survey (European Foundation for the Improvement of Living and Working Conditions). Luxembourg: Office for Official Publications of the European Communities.

Pascall, G., \& Kwak, A. (2005). Gender Regimes in Transition in Central and Eastern Europe. Bristol: Policy Press.

Peña-Casas, R., \& Pochet, P. (2009). Convergence and Divergence of European Working Conditions in Europe: 1990-2005. European Foundation for the Improvement of Living and Working Conditions. Luxembourg: Office for Official Publications of the European Communities.

Smith, M., Burchell, B., Fagan, C., \& O’Brien, C. (2008). Job quality in Europe. Industrial Relations Journal, 39(6): 586-603. 
Soskice, D. (1999). Divergent production regimes: Coordinated and uncoordinated market economies in the 1980s and 1990s. In: Kitschelt, H., Lange, P., Marks, G., \& Stephens, J. D. (eds.) Continuity and Change in Contemporary Capitalism (pp. 101-134). Cambridge: Cambridge University Press.

Soskice D (2005). Varieties of Capitalism and Cross-National Gender Differences. Social Politics 12 (2): 170-179.

Tangian, A. (2007). Is Work in Europe Decent? A Study Based on the 4th European Survey of Working Conditions 2005. Diskussionspapier Nr. 157. WSI in der Hans Böckler Stiftung.

Tåhlin, M. (2007). Skills and wages in European labour markets: Structure and change. In: Gallie, D. (ed.) Employment Regimes and the Quality of Work (pp. 35-76). New York: Oxford University Press.

Wallace, C., Pichler, F., \& Hayes, B. (2007). First European Quality of Life Survey: Quality of Work and Life Satisfaction. Dublin: European Foundation for the Improvement of Living and Working Conditions.

Wendorf, C. A. (2004). Primer on multiple regression coding: Common forms and the additional case of repeated contrasts. Understanding Statistics, 3(1): 47-57.

White, M., Hill, S., McGovern, P., Mills, C., \& Smeaton, D. (2003). 'High-Performance' Management Practices, Working Hours and Work-Life Balance, British Journal of Industrial Relations, 41(2): 175-195.

\section{End notes}

${ }^{1}$ We repeated our analyses with each of the three questions forming a task discretion index (whether or not they were able to choose or change the order of their tasks, the methods of work, and the speed or rate of work). The decline in Sweden between last two waves was evident for all three questions. The increase of task discretion in Finland was also evident for all three measures, but it was especially strong with regard to ability to change the speed of work. 